\title{
Functional fat body proteomics and gene targeting reveal in vivo functions of Drosophila melanogaster $\alpha$-Esterase- 7
}

\author{
Ruth Birner-Gruenberger $^{c}$, Iris Bickmeyer ${ }^{\mathrm{a}}$, Julia Lange ${ }^{\mathrm{a}, 1}$, Philip Hehlert ${ }^{\mathrm{a}, \mathrm{b}}$, Albin Hermetter ${ }^{\mathrm{d}}$, \\ Manfred Kollroser ${ }^{\mathrm{e}}$, Gerald N. Rechberger ${ }^{\mathrm{f}}$, Ronald P. Kühnlein ${ }^{\mathrm{a}, \mathrm{b}, *}$ \\ a Abteilung Molekulare Entwicklungsbiologie, Max-Planck-Institut für biophysikalische Chemie, Am Fassberg 11, 37077 Göttingen, Germany \\ ${ }^{\mathrm{b}}$ Forschungsgruppe Molekulare Physiologie, Max-Planck-Institut für biophysikalische Chemie, Am Fassberg 11, 37077 Göttingen, Germany \\ ${ }^{\mathrm{c}}$ Research Group Functional Proteomics, Institute of Pathology, and Proteomics Core Facility, Center of Medical Research, Medical University of Graz, Stiftingtalstrasse 24, \\ 8010 Graz, Austria \\ dinstitute of Biochemistry, Graz University of Technology, Petersgasse 12, 8010 Graz, Austria \\ e Institute of Forensic Medicine, Medical University of Graz, Universitätsplatz 4, 8010-Graz, Austria \\ ${ }^{\mathrm{f}}$ Institute of Molecular Biosciences, Karl-Franzens-University of Graz, Humboldtstrasse 50, 8010-Graz, Austria
}

\section{A R T I C L E I N F O}

\section{Article history:}

Received 18 September 2011

Received in revised form

7 December 2011

Accepted 8 December 2011

\section{Keywords:}

Drosophila

$\alpha$-Esterase-7

Mutant

Insecticide

Proteomics

Fat body

\begin{abstract}
A B S T R A C T
Carboxylesterases constitute a large enzyme family in insects, which is involved in diverse functions such as xenobiotic detoxification, lipid metabolism and reproduction. Phylogenetically, many insect carboxylesterases are represented by multienzyme clades, which are encoded by evolutionarily ancient gene clusters such as the $\alpha$-Esterase cluster. Much in contrast to the vital importance attributed to carboxylesterases in general, the in vivo function of individual $\alpha$-Esterase genes is largely unknown. This study employs a functional proteomics approach to identify esterolytic enzymes of the vinegar fly Drosophila melanogaster fat body. One of the fat body carboxylesterases, $\alpha$-Esterase-7, was selected for mutational analysis by gene targeting to generate a deletion mutant fly. Phenotypic characterization of $\alpha$-Esterase-7 null mutants and transgenic flies, which overexpress a chimeric $\alpha$-Esterase-7:EGFP gene, reveals important functions of $\alpha$-Esterase-7 in insecticide tolerance, lipid metabolism and lifespan control. The presented first deletion mutant of any $\alpha$-Esterase in the model insect $D$. melanogaster generated by gene targeting not only provides experimental evidence for the endogenous functions of this gene family. It also offers an entry point for in vivo structure-function analyses of $\alpha$-Esterase-7, which is of central importance for naturally occurring insecticide resistance in wild populations of various dipteran insect species.
\end{abstract}

(c) 2011 Elsevier Ltd. All rights reserved.

\section{Introduction}

Carboxylesterases (CEs) play essential roles in lipid and xenobiotic metabolism throughout the animal kingdom. The broad substrate spectrum and their complex expression profiles reflect functional diversification among members of the CE multigene

Abbreviations: CE, carboxylesterase; D.m., Drosophila melanogaster; LD, lipid droplet; L.c., Lucilia cuprina; NBD-HE-HP, O-((6-(7-nitrobenz-2-oxa-1,3-diazol-4-yl) amino)hexanoyl)-aminoethyl-O-(n-hexyl)phosphonic acid p-nitrophenyl ester; OP, organophosphorous; qRT-PCR, quantitative reverse transcription PCR; s.e.m., standard error of the mean.

* Corresponding author. Forschungsgruppe Molekulare Physiologie, Max-PlanckInstitut für biophysikalische Chemie, Am Fassberg 11, 37077 Göttingen, Germany. Tel.: +49 (0) 551 2011045, fax: +49 (0) 5512011755.

E-mail address: rkuehnl@gwdg.de (R.P. Kühnlein).

1 Present address: ICON Clinical Research, Heinrich-Hertz-Straße 26, 63225 Langen, Germany. family, which promotes organismal diversity during Metazoan evolution (reviewed in Oakeshott et al., 1999). Insect genomes are particularly rich in CE genes and this complexity has been correlated with important organismic functions such as the insecticide resistance in the malaria vector Anopheles gambiae (Ranson et al., 2002). Overexpression has been described as one of two CEmediated strategies for metabolic detoxification of organophosphorous (OP) insecticides found in insecticide-resistant populations of dipteran species (reviewed in Bass and Field, 2011; Oakeshott et al., 2005). This strategy makes use of OP sequestering to protect against the neurotoxic effect of the insecticides on their target, acetylcholinesterase. Alternatively, CE mutants with novel substrate spectrum are employed to detoxify OP insecticides by hydrolytic cleavage (see Section 4). Generally, much in contrast to the vital general importance of CEs, functional information about the in vivo role of particular CE family members is limited. 
Electrophoretic zymograms of adult Drosophila melanogaster flies identified 22 soluble esterase isozymes, among them ten CEs (Healy et al., 1991). On the other hand computational annotation of the fly genome lists 35 genes, which encode enzymes with experimentally supported or predicted carboxylesterase activity (GO term 0004091; Tweedie et al., 2009; www.flybase.org). Among them are the ten genes ( $\alpha$-Est1-10) of the $\alpha$-Esterase cluster located on the right arm of chromosome 3. Recently, the first two $\alpha$-Est genes were assigned to esterase isozyme activities, i.e. $\alpha$-Est5 to EST9 and $\alpha$-Est7 to EST23 by peptide fingerprinting combined with recombinant protein expression (Campbell et al., 2003). This approach started to link the wealth of biochemical information on EST isozymes to the molecular identity of the corresponding genes. However, the in vivo roles of individual $\alpha$-Est cluster genes remains obscure as none of them has been functionally characterized by mutant analysis.

Correlational analyses support diverse functions for $\alpha$-Est genes. For example, $\alpha$-Est $1, \alpha$-Est 2 and $\alpha$-Est 8 have a pronounced expression in adult fly heads (Campbell et al., 2003; Chintapalli et al., 2007). In heads of adult males $\alpha$-Est 1 and $\alpha$-Est 8 are transcriptionally up-regulated in fly lines selected for aggressive behavior (Dierick and Greenspan, 2006) and $\alpha$-Est2 behaves as a matingresponsive gene (Ellis and Carney, 2010). Moreover, the $\alpha$-EST2 and $\alpha$-EST7 proteins are members of the fat body lipid droplet proteome (Beller et al., 2006) suggesting a role in lipid metabolism. Notably, seven of the ten $\alpha$-Esterase cluster genes are at least moderately expressed in the Drosophila fat body (Chintapalli et al., 2007). Multiple $\alpha$-Est gene expression in the fat body highlights its central role of this organ as a metabolic hub in insects. Besides its most prominent role as major energy storage organ, the fat body is involved in vital organismal functions such as immunity, growth control and detoxification. The role of particular esterase activities in these processes awaits clarification.

This study employs a functional proteomics approach to molecularly identify esterases of the Drosophila fat body. Tissue profiling for esterase activities with subsequent enzyme identification via mass spectrometry has been successfully applied to characterize the lipolytic proteomes of mouse adipose tissue (Birner-Gruenberger et al., 2005) and liver (Birner-Gruenberger et al., 2008) as well as serine hydrolases up-regulated in invasive cancers (Nomura et al., 2010). Recognition of esterases is realized by activity-based probes, which contain $p$-nitrophenyl or fluoro phosphonates as reactive groups for the serine in the active site of the target enzymes as well as a fluorescent or biotin reporter tag for detection.

One of the major fat body esterases toward the activity-based probe NBD-HE-HP, which was identified in this study, $\alpha$-Est7, was subjected to in vivo mutational analysis by homologous recombination. Initial phenotypic characterization of $\alpha$-Est7 mutant flies provides evidence that the gene is not essential for the Drosophila development but serves important functions for insecticide tolerance, lipid metabolism and lifespan control.

\section{Material and methods}

\subsection{Functional proteomics}

Fat body cells from young adult male flies (0-14 h of age) of the reference strain (RKF778; $6 \mathrm{~h}$ food deprived) were released into $25 \mathrm{mM}$ Tris/HCl pH7.5, $0.25 \mathrm{M}$ sucrose, $1 \mathrm{mM}$ EDTA, $1 \mathrm{mM}$ DTT, $20 \mu \mathrm{g} / \mathrm{ml}$ leupeptin, $2 \mu \mathrm{g} / \mathrm{ml}$ antipain, $1 \mu \mathrm{g} / \mathrm{ml}$ pepstatin by manual opening of the fly abdomina. The cells were lysed by repeated freeze/thaw cycles and intense vortexing followed by centrifugation of the homogenate at $5000 \mathrm{~g}$ for $15 \mathrm{~min}$. The protein content of the cytoplasmic layer between the fat layer and the pellet was determined (Bio-Rad Protein Assay \#500-0006) and adjusted to $0.5 \mu \mathrm{g} / \mu \mathrm{l}$. Homogenates were incubated with $20 \mu \mathrm{M}$ the fluorescent activity-based probe O-((6-(7-Nitrobenz-2-oxa-1,3-diazol-4-yl) amino)hexanoyl)aminoethyl-O-(n-hexyl)phosphonic acid $p$-nitrophenyl ester (NBD-HE-HP) (synthesized as published in Oskolkova et al., 2003; Schmidinger et al., 2005) and $1 \mathrm{mM}$ Triton X-100 for $2 \mathrm{~h}$ at $28{ }^{\circ} \mathrm{C}$ with mild shaking $(550 \mathrm{rpm})$, quick-frozen in liquid nitrogen and kept at $-20{ }^{\circ} \mathrm{C}$ until further use. Unlabeled controls were also tested to exclude autofluorescent proteins. Proteins were precipitated with $10 \%$ trichloroacetic acid (w/v) and subjected to SDS-PAGE in Tris/glycine buffer (5\% stacking gel, 10\% resolving gel) or 2D-gel electrophoresis (pH 3-10 NL IPG strips; 10\% SDS-PAGE) for detection of fluorescent NBD-HE-HP-labeled protein bands/ spots by laser scanning as described (Birner-Gruenberger et al., 2005). Relative fluorescence intensity spot volumes were determined using Delta2D 4.0.8 software for spot detection and quantitation after normalization on the total fluorescence intensity of all detected spots.

Protein spots were excised from gels and tryptically digested according to the method by Shevchenko et al. (1996). Peptide extracts were dissolved in $0.1 \%$ formic acid, separated by nanoHPLC and analyzed by LC-MS/MS with a Thermo-Finnigan LTQ linear iontrap mass spectrometer as described (Birner-Gruenberger et al., 2008). Proteins were identified by searching the $D$. melanogaster NCBI non-redundant public database with SpectrumMill Rev. 03.03.078 (Agilent). Acceptance parameters were two or more identified distinct peptides according to the parameters defined by Carr et al. (2004) except for the single high confident peptide of $\alpha$ EST2 (see Fig. S1).

\subsection{Esterase activity assay}

Fat body cell homogenates were essentially prepared as described in Section 2.1. Specific total esterase activity was determined from the linear increase of absorbance at $405 \mathrm{~nm}$ of $p$ nitrophenolate released from $100 \mu \mathrm{M} p$-nitrophenyl butyrate in $20 \mathrm{mM}$ Tris- $\mathrm{HCl}, \mathrm{pH} 8,150 \mathrm{mM} \mathrm{NaCl}$ and 0.01\%Triton X-100 (Shirai and Jackson, 1982).

\subsection{Fly techniques}

The Act5C-Gal4 fly stock (BDSC \#4414) is available from the Bloomington Drosophila Stock Center. The FB-Gal4 inducer (RKF125; Grönke et al., 2003), the $\alpha$-Est7:EGFP (formerly CG1112:EGFP) effector fly strain (RKF736; Beller et al., 2006) and the reference stock used for functional proteomics (RKF778; Grönke et al., 2007) have been described earlier. All flies were propagated at $25{ }^{\circ} \mathrm{C}$ on a complex malt-soy flour-corn flour-molasses food as described (Grönke et al., 2005).

The $\alpha$-Est7 $7^{1}$ mutant allele lacks genomic sequences from 3R $3,345,260$ to $3,347,419$ and was generated by ends-out gene targeting as described (Gong and Golic, 2003). In brief, oligonucleotide primer pairs RKO535/536 (see Fig. 2A for primer positions and Supplemental Material and Methods for primer sequences) and RKO537/538 were used to amplify genomic regions flanking $\alpha$-Est7 exons 2-6 from the $w^{1118}$ fly stock (RKF972; called $\alpha-E s t 7^{+}$control; Grönke et al., 2009), which were cloned via pBS-70w into the pP \{EndsOut2\} donor vector (both plasmids were a gift from Jeff Sekelsky; for details on the vectors see http://sekelsky.bio.unc.edu/ research/vectors/vectors.html). Transgenic lines carrying the $p P$ \{EndsOut2\} $\alpha$-Est7 $w^{+}$donor were established in the RKF972 genetic background and crossed to $y^{1} w^{*} ; P\left\{r y^{+t 7.2}=70 F L P\right\} 11 P\left\{v^{+t 1.8}=70 I-\right.$ SceI\}2B noc ${ }^{\mathrm{Sco}} / \mathrm{CyO}, S^{2}$ (BDSC \#6934), which provides heat shockinducible I-SceI nuclease and FLP recombinase expression. Heat shock $\left(1 \mathrm{~h} 38^{\circ} \mathrm{C}\right)$ was performed at day 3 after egg laying and 
mosaic $w^{+}$F1 virgins were crosses to $w^{1118} ; P\left\{r y^{+t 7.2}=70 F L P\right\} 10$ (BDSC \#6938), which provides a constitutive FLP source. From more than 1200 individual lines, which were established from F2 flies with homogenous $w^{+}$eye color one mutant stock was singled out after a selection/characterization scheme detailed in Supplemental Material and Methods. Finally, the stock $w^{1118} ; \alpha$-Est7 $7^{1}$ (RKF973) was established by backcrossing to $\alpha-E s t 7^{+}$for four generations to achieve a genetically-adjusted mutant-control pair.

\subsection{Body lipid content assay}

Male flies were fed for six days after hatching at $25{ }^{\circ} \mathrm{C}$ under $12 \mathrm{~h}: 12 \mathrm{~h}$ light/dark conditions on the propagation food and the body fat assayed on triplicate samples of eight males each using a commercial Triglyceride assay substrate as described (Grönke et al., 2003; Hildebrandt et al., 2011).

\subsection{Longevity assay}

Longevity assays have been performed as described (Grönke et al., 2005). In brief, $n=180$ male flies (12 replicates of cohorts of 15 flies) for each genotype were set up and incubated at $25{ }^{\circ} \mathrm{C}$ with a $12 \mathrm{~h}: 12 \mathrm{~h}$ light/dark cycle. The food was changed every 2-3 days and the surviving flies were scored at these points in time. Data plotted in Fig. 4 represent age-specific average survivorship rate means (in \%) with $95 \%$ confidence intervals calculated from the replicates. A log-rank test was performed to assess statistical significance of the observed differences between the $\alpha-E s t 7^{1}$ and the $\alpha$-Est $7^{+}$survivorship data.

\subsection{Fecundity assay}

Single virgin female flies of the respective genotypes were mated to 2-3 males of the same genotype. Flies were flipped to fresh food every 3-4 days and the F1 generation was allowed to develop until imaginal hatching. Pupal cases were scored to calculate the cumulative number of progeny per female fly.

\subsection{Insecticide tolerance assay}

Equal numbers of mutant and control embryos were mixed and raised in the same food vials. Male flies were fed for six days after hatching and subjected to a 4-6 h water-only starvation period. Cohorts of ten starved flies of each genotype were transferred to vials without fly food but equipped with a piece of Whatman paper soaked with $5 \%$ sucrose $/ 5 \%$ Brilliant blue (www.omya-peralta.de) and the diazinon (Riedel-de-Haen 45842) insecticide parent molecule or solvent control (2\% Acetonitrile for all conditions). Survival times were monitored and the survivor rates calculated on the basis of triplicate or duplicate (solvent controls) measurements. Qualitative food uptake was controlled by brilliant blue staining of the gut.

\subsection{Fluctuating asymmetry analysis}

Right-left distribution of large and small sternopleural bristle numbers were used to score for fluctuating asymmetry (FA) according to previously described parameters (Palmer and Strobeck, 1986; Parsons, 1962). There was no evidence of directional asymmetry or antisymmetry, and no size-dependent correlation for the analyzed asymmetry values, following a descriptive statistical analysis in male $\alpha$-Est $7^{+}$or $\alpha$-Est $7^{1}$ flies raised at equal density in the same food vials at $25^{\circ} \mathrm{C}$. As both large and small sternopleural bristles showed an FA character they were used to estimate the developmental stability. The asymmetry index calculated was the sum of the absolute differences between right and left side of an individual divided by the sample size (Polak et al., 2004):

$\mathrm{FA}=\frac{\sum\left(\left|R_{i}-L_{i}\right|\right)}{N}$

A univariate analysis of variances was performed to examine differences between the $\alpha$-Est7 mutant and $\alpha$-Est $7^{+}$control population. All analyses were performed using OriginPro v.8.0724.

\subsection{Quantitative RT-PCR}

Quantitative RT-PCR analysis was performed as described in Beller et al. (2010), using the QuantiTect Primer Assays QT00970193 for $\alpha$-Est7, QT00970200 for $\alpha$-Est6, QT00970186 for $U b c 84 D$ and QT00985677 for RpL32, respectively (www.quiagen.com).

\subsection{Molecular biology}

\subsubsection{Inverse $P C R$}

Genomic DNA equivalent to two flies of the mutant stock $\alpha$-Est7 ${ }^{1}$ (RKF973) and the $\alpha$-Est7 $7^{+}$control (RKF972), respectively, were subjected to cleavage by $20 \mathrm{U}$ of restriction endonuclease Hin6I in a total volume of $25 \mu$ l. Endonucleolytic cleavage was terminated by a heat inactivation step $\left(10 \mathrm{~min}\right.$ at $65^{\circ} \mathrm{C}$ ) and $10 \mu \mathrm{l}$ of the reaction was ligated overnight in a total volume of $400 \mu \mathrm{l}$ with T4 DNA ligase at $8{ }^{\circ} \mathrm{C}$. The ligation reaction was ethanol-precipitated, the pellet washed in $70 \%$ ethanol and subsequently resuspended in $150 \mu \mathrm{l}$ Tris-EDTA. Of the ligation products $15 \mu \mathrm{l}$ each were subjected to PCR reactions using the primer pairs RKO782/783 (gene targeting construct $5^{\prime}$ border) or RKO784/785 (gene targeting construct $3^{\prime}$ border), respectively (PCR program: 30sec $95^{\circ} \mathrm{C}, 30 \mathrm{sec} 60^{\circ} \mathrm{C}, 2 \mathrm{~min}$ $68{ }^{\circ} \mathrm{C}$; 38 cycles). Resulting amplicons were size-separated on a $1 \%$ agarose gel and visualized by ethidium bromide staining. Note that approximate positions of primer binding sites are shown in Fig. $2 \mathrm{~A}$ and primer sequences are presented in Supplemental Material and Methods. Calculated sizes: $5^{\prime}$ donor construct border on endogenous white gene of $\alpha$-Est7 $7^{1}$ and the $\alpha$-Est7 $7^{+}: 594 \mathrm{bp}$. On $\alpha$-Est7 of $\alpha$ $E s t 7^{1}$ only: 902 bp. $3^{\prime}$ donor construct border on $\alpha$-Est7 of $\alpha$-Est $7^{1}$ only: $364 \mathrm{bp}$.

\subsection{Statistical analysis}

If not stated otherwise replicates were expressed as average values with corresponding standard deviation. Statistical significance was tested by unpaired Students' $t$-tests.

\section{Results}

\subsection{Functional proteomics of Drosophila fat body esterases}

A functional lipolytic proteome approach was used to identify esterases in the fat body cells of young adult $D$. melanogaster flies. To this aim fat body cell homogenates were incubated with the fluorescent activity-based esterase probe NBD-HE-HP (for details see Section 2.1). Separation of the homogenate on 2D SDS-PAGE and subsequent detection of about 15 fluorescent spots (Fig. 1A) revealed about ten labeled proteins. Eight of these proteins were identified by LC-MS/MS analysis by multiple peptides and one by a single high confident peptide (Fig. 1B). Among these nine identifications are four proteins with the gene ontology annotated carboxylesterase activity according to gene ontology (GO term 0004091). These are three enzymes encoded by the Drosophila $\alpha$ Esterase cluster i.e. $\alpha$-Esterase-7, $\alpha$-Esterase-5, $\alpha$-Esterase- 2 and 
A

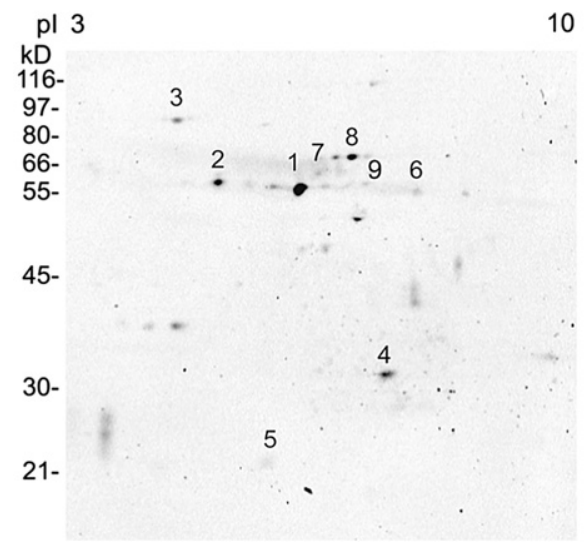

B

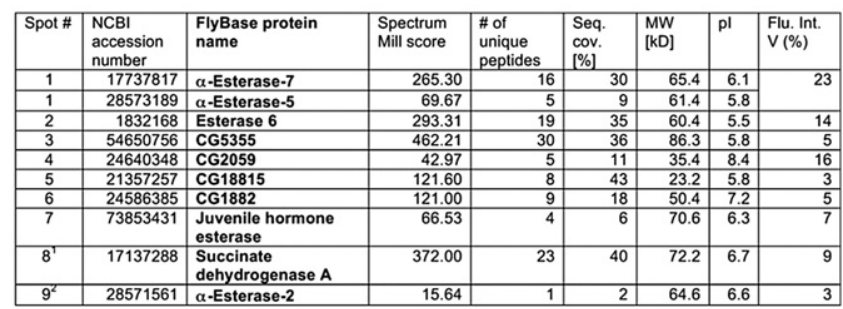

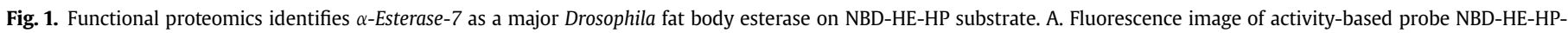

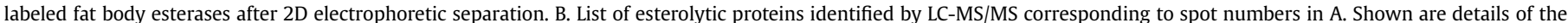

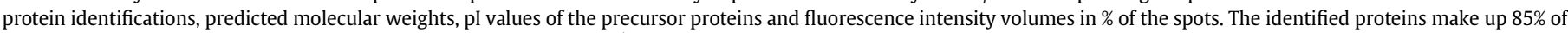

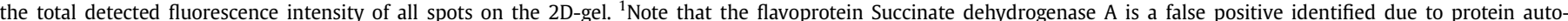

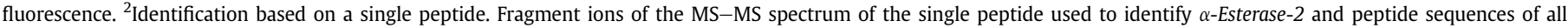
identified unique peptides are shown in Fig. S1.

Esterase 6, which is encoded by the Drosophila $\beta$-esterase gene cluster. Additionally, the proteomics approach identified Juvenile hormone esterase as well as four in silico predicted, functionally largely uncharacterized proteins. These proteins are members of the esterase/lipase superfamily (annotation cI12031) (MarchlerBauer et al., 2011) called CG5355, CG2059, CG1882 and CG18815. CG5355 encodes a predicted prolyl oligopeptidase domain (pfam0297) and CG2059 encodes a predicted acyl-CoA esterase domain (region name PRK10673). CG1882 is a predicted $\alpha \beta$ fold family protein (region name PLN02894) and CG18815 encodes a predicted $\alpha \beta$ hydrolase 2 domain protein (pfam02230) with putative thioesterase activity. All of these functionally uncharacterized proteins will be discussed in more detail below (Section 4; for details on the LC-MS/MS-based protein identifications see Fig. S1).

The most intensely labeled protein using the NBD-HE-HP probe (spot 1 in Fig. 1A) corresponds to the gene product of the $\alpha$-Esterase7 ( $\alpha$-Est7) gene (also called CG1112; www.flybase.org). The protein product of $\alpha$-Est7, $\alpha$-Esterase-7 ( $\alpha$-EST7) is a membrane-associated $\alpha$-Esterase with preference for substrates with shorter acid side chain length (Spackman et al., 1994; Parker et al., 1996). Inhibitor sensitivity studies classify $\alpha$-EST7 as subclass I CE (Spackman et al., 1994). Intense labeling of $\alpha$-EST7 by NBD-HE-HP (Fig. 1A) suggests tight binding of this suicide substrate and/or high protein abundance and is consistent with the pronounced transcriptional expression of the $\alpha$-Est7 gene in the fat body (Chintapalli et al., 2007; Campbell et al., 2003). Collectively these data predict $\alpha$ Est7 to encode one of the major Drosophila fat body esterases with hitherto unknown function in vivo.

\subsection{Generation of Drosophila $\alpha$-Esterase-7 mutant by gene targeting}

Cytogenetically $\alpha$-Est7 is a central member of the esterase gene cluster on the right arm of $D$. melanogaster chromosome 3 . The $\alpha$ Est7 gene is flanked by its paralogue $\alpha$-Esterase- 6 ( $\alpha$-Est6) and by the Ubiquitin conjugating enzyme $84 D$ (Ubc84D) gene (Fig. 2A). To aid the characterization of $\alpha$-Est7 gene function in vivo, gene replacement by homologous recombination was used to generate the deletion mutant $\alpha$-Est7 $7^{1}$, which lacks all but the first exon of the $\alpha$-Est7 gene (Fig. 2A). The absence of $\alpha$-Est7 transcript in the $\alpha$-Est7 $7^{1}$ mutant and the lack of impairment of $\alpha$-Est6 and Ubc84D expression have been assessed by qRT-PCR (Fig. 2B). The successful deletion of $\alpha$-Est7, has been genomically confirmed by PCR genotyping (Fig. 2C) and sequencing (Fig. S3). The absence of additional donor construct integrations outside the $\alpha$-Est7 locus was verified by inverse PCR (Fig. 2D; Section 2.10; for details of all approaches to characterize the $\alpha$-Est $7^{1}$ mutant see Supplemental Material and Methods). Consistent with the deletion of $\alpha$-Est7, fat body homogenates of $\alpha$-Est $7^{1}$ mutant flies lack the dominant esterase, which binds the NBD-HE-HP probe in genetically matched control homogenates $\left(\alpha-E s t 7^{+}\right)$(Fig. 2E). The apparent molecular weight of the corresponding enzyme matches well with the predicted molecular weight of $\alpha$-EST7 of $65.4 \mathrm{kDa}$ as well as to the apparent molecular weight of recombinantly expressed $\alpha$-EST7 (Campbell et al., 2003). Conversely, transgenic overexpression of a $\alpha$ EST7:EGFP fusion protein (Beller et al., 2006) using the UAS/GAL4 technique (Brand and Perrimon, 1993) results in a strong esterase activity on $p$-nitrophenyl-butyrate conferred by a protein species, which matches the predicted fusion protein size of about $92 \mathrm{kDa}$ (Fig. 2E). Lack of $\alpha$-Est7 causes a drastic reduction of total fat body esterase activity on $p$-nitrophenyl butyrate by $48 \%$ (Fig. 2F). Conversely, overexpression of a $\alpha$-EST7:EGFP fusion protein increases total esterase activity on $p$-nitrophenyl-butyrate by $48-78 \%$ compared to controls (Fig. 2F). Collectively, these loss-offunction and gain-of-function studies demonstrate that $\alpha$-Est7 is a major contributor to total esterase activity on $p$-nitrophenylbutyrate in the fly fat body.

\subsection{Control of insecticide tolerance, lipid storage and lifespan by Drosophila $\alpha$-Esterase-7}

$\alpha$-Esterase-7 has been proposed to act in xenobiotic metabolism based on its expression during Drosophila feeding stages (Campbell et al., 2003). Importantly, $\alpha$-Est7 orthologs of higher dipterans such as the blowfly Lucilia cuprina and the housefly Musca domestica have been implicated in OP insecticide detoxification in resistant insect strains (Newcomb et al., 1997; Claudianos et al., 1999). In these species metabolic OP detoxification is based on mutant $\alpha$-Est7 enzymes with modified substrate spectrum (Heidari et al., 2004). However, a dose/activity-dependent modulation of OP insecticide tolerance by wild type $\alpha$-Est7 has not been addressed in vivo. To 
directly assess the impact of $\alpha$-Est7 activity in Drosophila, $\alpha$-Est7 loss-of-function and gain-of-function flies were exposed to varying doses of diazinon, an organophosphorothioate, which becomes bioactivated to the OP insecticide diazoxon (Fig. 3). Consistent with a protective role of $\alpha$-Est7 toward the insecticide parent molecule, $\alpha$-Est $7^{1}$ mutants are weakly diazinon-sensitive (Fig. 3A). Conversely, ubiquitous transgenic overexpression of $\alpha$-Est7 confers moderate insecticide tolerance (Fig. 3B). Collectively, these data present in vivo evidence for a role of wild type $\alpha$-Est7 in insecticide tolerance control in D. melanogaster.

Besides its role in detoxification of xenobiotics, $\alpha$-Est7 has been hypothesized to act in dietary lipid metabolism based on the expression profile of the gene (Campbell et al., 2003). Accordingly, the body fat content has been quantified as a diagnostic marker of dysregulation of neutral lipid metabolism. Consistent with a lipid metabolism function of $\alpha$-Est7, the lipid stores of $\alpha$-Est $7^{1}$ mutant flies are significantly reduced by $24 \%$ (Fig. 4 A). A body fat reduction of this magnitude is not attributable to genetic background effects in Drosophila strains, which are as closely related as the $\alpha$-Est $7^{1}$ and $\alpha-E s t 7^{+}$stocks used in this study. In contrast to the mutant phenotype, fat body-targeted $\alpha$-EST7:EGFP overexpression has no significant impact on body fat storage (Fig. 4A) suggesting that the $\alpha$-Est7 in vivo function on lipid metabolism is not restricted to the fat body. Currently it is unknown how the $\alpha$-EST7 enzymatic function promotes storage fat accumulation (for a detailed discussion see Section 4).

The storage lipid metabolism function as well as pronounced expression of the $\alpha$-Est7 in the female spermatheca (Chintapalli et al., 2007) suggests that the gene might influence reproductive fitness. However, offspring counts demonstrate no effect on female fecundity in $\alpha$-Est7 $7^{1}$ mutant flies (Fig. 4B). But then, flies lacking $\alpha$ Est7 function suffer from a median lifespan reduction between $6 \%$ and $14 \%$ (Fig. 4C and Fig. S2), which predicts a selective disadvantage of $\alpha$-Est7 mutant flies in a natural environment. It should be noted that the genetic background of the $\alpha$-Est7 mutant and corresponding control have been adjusted by a limited number of backcrosses. Accordingly, genetic background effects on the extent of the described physiological phenotypes cannot be ruled out. Collectively, these data demonstrate that $\alpha$-Est7 is not essential for the development of the fly. However, the gene is necessary for selected physiological functions, which impact on genetic fitness parameters.

$\alpha$-Esterase- 7 has been proposed to provide a developmental function. This hypothesis is based on the finding of increased fluctuating asymmetry (FA), i.e. morphological left-right differences in specific bristle characters, in OP insecticide-resistant strains of Lucilia, which carry ali-esterase mutant alleles (Clarke et al., 2000; Davies et al., 1996; McKenzie and Clarke, 1988; McKenzie et al., 1982). Fluctuating asymmetry is indicative of developmental instability, which is believed to cause selective disadvantages and correspondingly a genetic fitness decline. Drosophila flies lacking $\alpha$-Est7 show no gross developmental defects or impairment in fecundity. Small and large sternopleural bristle counts were used to test for an increase of FA in $\alpha$-Est7 Drosophila mutants. Mean asymmetry values ( \pm s.e.m.) for all sternopleural bristles of $n=154$ flies per genotype were $2.00 \pm 0.105$ for $\alpha$-Est $7^{1}$ mutants and $2.23 \pm 0.123$ for $\alpha$-Est $7^{+}$control flies, respectively. Differences between the FA levels were not statistically different between the two genotypes (Levene's test $p=0.86$ ). This result argues that the lack of $\alpha$-Est7 function does not cause developmental instability in Drosophila.

Taken together this study molecularly identifies major esterases on the activity-based NBD-HE-HP probe in the Drosophila fat body based on a functional proteomics approach. $\alpha$-Esterase-7, the most prominent fat body esterase toward the NBD-HE-HP suicide substrate, was selected to generate the first molecularly characterized Drosophila deletion mutant lacking a single $\alpha$-Est gene by gene targeting. The initial mutant phenotype analysis provides evidence that $\alpha$-Est7 confers moderate insecticide tolerance in wild type Drosophila flies. Moreover, although $\alpha$-Est7 is not an essential gene it is implicated in important organismal functions in flies such as body fat storage and lifespan control. Accordingly, this study provides an entry point to a more comprehensive understanding of the biological functions of the esterase multigene family in insects.

\section{Discussion}

The fat body functional proteomics screen identified several enzymes with putative, yet uncharacterized roles in $D$. melanogaster metabolism. Among them are four predicted esterase/ lipase superfamily (annotation cI12031) members: CG5355, CG2059, CG18815 and CG1882.

CG5355 is an ubiquitously expressed gene and encodes an $86.3 \mathrm{kDa}$ protein with predicted prolyl oligopeptidase domain (pfam0297) (Chintapalli et al., 2007; Marchler-Bauer et al., 2011). The protein is well sequence-conserved among the Drosophilids (e.g. sequence identity to Drosophila virilis GJ21822 is $83.0 \%$ ). Moreover, several Sophophoran Drosophilid species encode a CG5355 paralog of identical domain structure but unknown function, which is called CG2528 in D. melanogaster $(69.9 \%$ sequence identity to CG5355). More distantly but still very closely related CG5355 homologs are encoded by the genomes of the body louse (54.5\% identity) and the honeybee (60.5\% identity; for more details see Fig. S4).

Another protein identified by the functional proteomics approach is CG2059, a functionally uncharacterized protein (calculated mass $35.4 \mathrm{kDa}$ ), which contains a predicted acyl-CoA esterase domain (region name PRK10673). Sequence alignments with related proteins show, that CG2059 is evolutionarily conserved among insect species (Fig. S4). Among the Drosophilids, which are distantly related to $D$. melanogaster, the Hawaiian Drosophila species Drosophila grimshawi encodes the putative protein GH24258, which has $48.2 \%$ sequence identity to D.m. CG2059 and among the Culicidae, A. gambiae encodes AGAP009289-PA, which is $39.6 \%$ identical to the D.m. protein (for more sequence similarity information see Fig. S4). The human protein with highest sequence similarity to D. melanogaster CG2059 is called $\alpha \beta$ hydrolase domain containing 11 (ABHD11; also called WBSCR21 for Williams-Beuren syndrome chromosome region 21). Notably, mouse ABHD11 (sequence identity to D.m. CG2059 is $33.3 \%$ ) is repressed in white adipose tissue (WAT) upon high fat diet feeding but induced by adding the PPAR $\gamma$ agonist rosiglitazone to the diet (Shen et al., 2007). In this tissue ABHD11 is co-regulated with the lysophosphatidic acid acyltransferase ABHD5 (also called the Chanarin-Dorfman syndrome gene or CGI-58) (Ghosh et al., 2008), which is the well-established activator of adipose triglyceride lipase (ATGL, also called PNPLA2) (Lass et al., 2006). ATGL is the vertebrate ortholog of the $D$. melanogaster Brummer lipase (Grönke et al., 2005). Interestingly, the presented functional proteomics approach also identified CG1882, which is encoded by the only Drosophila homolog of the vertebrate paralogous gene pair ABHD5/CGI-58 and ABHD4 (sequence identities $46.6 \%$ and $47.5 \%$, respectively; see Fig. S4). Since CG1882 is expressed in the fat body and the protein localizes on the surface of lipid droplets (Cermelli et al., 2006) it is tempting to speculate that the gene executes a lipid metabolic function, either autonomously or in cooperation with the Brummer triglyceride lipase. The hypothesis of an evolutionarily ancient role of CG1882 in lipid metabolism gains further support by the finding that a mutation in the sequence-related Arabidopsis thaliana gene At4g24160 (amino acid sequence 
A

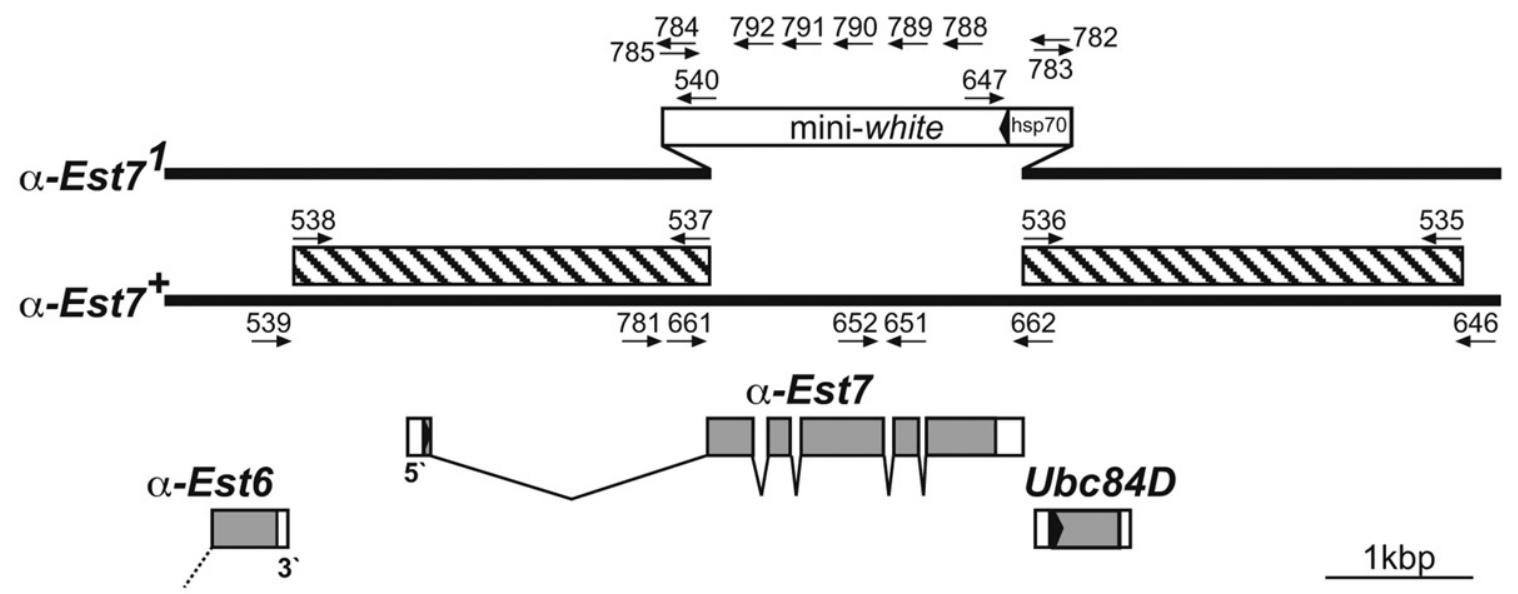

B

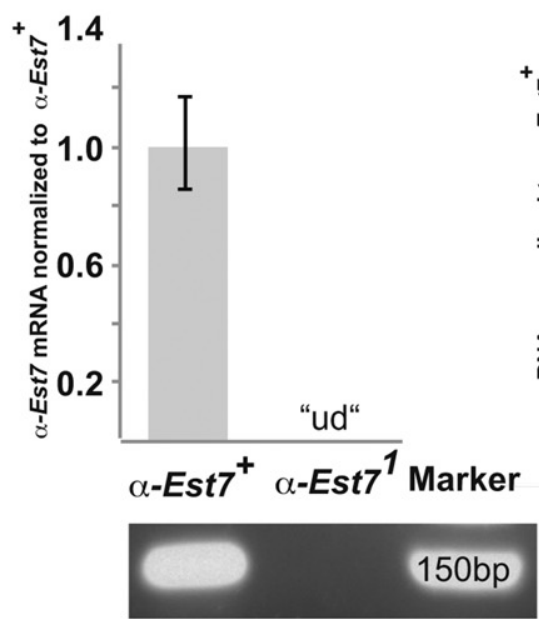

E

$\mathrm{kDa}$

130

95

72

55

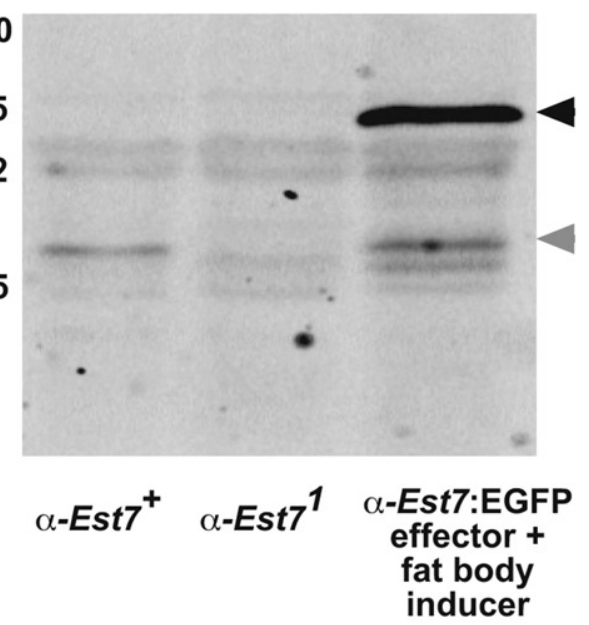

control mutant overexpression
C
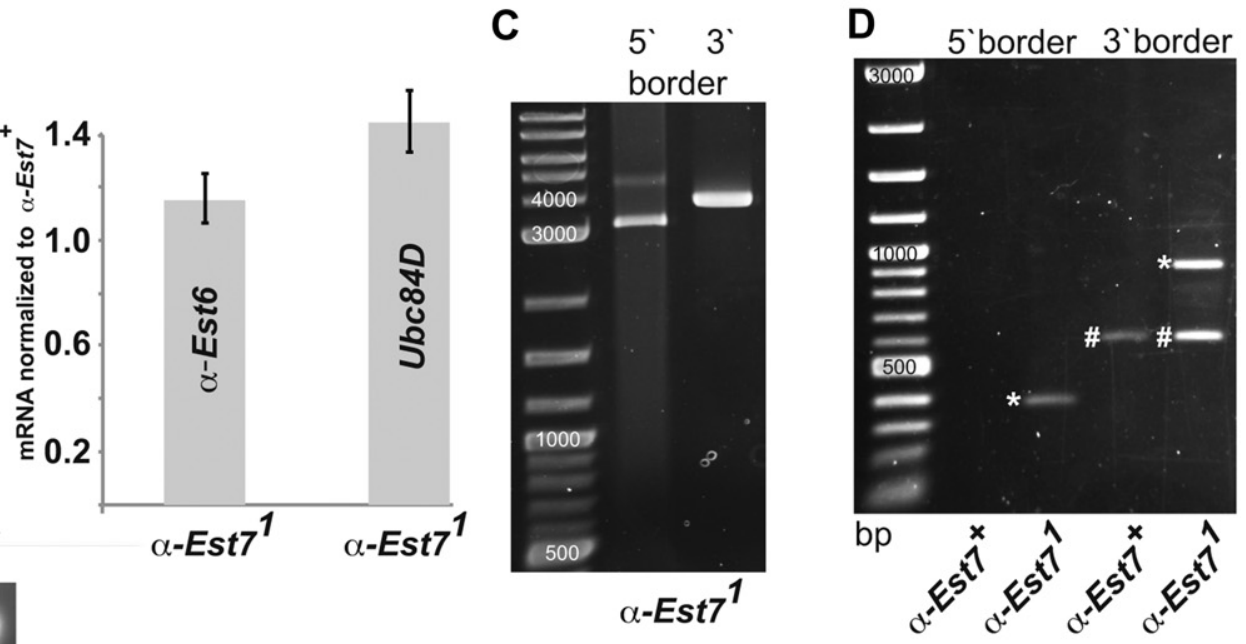

$\mathbf{F}$

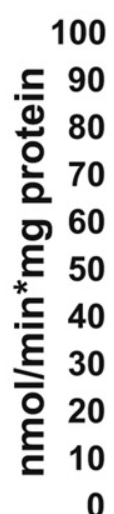

$\alpha-E s t 7^{+} \quad \alpha-E s t 7^{1}$

control mutant

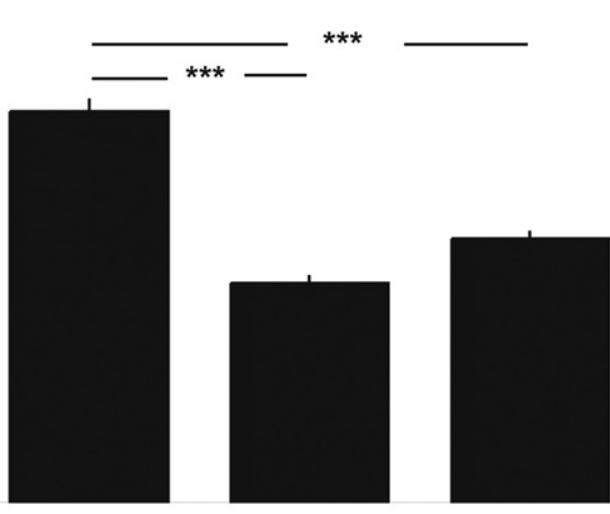
$\alpha$-Est7:EGFP $\alpha$-Est7:EGFP fat body effector + fat body effector inducer inducer overexpression contro control 
A

- $\alpha-E s t 7^{1}$

$\Delta \alpha-E s t 7^{+}$(control)

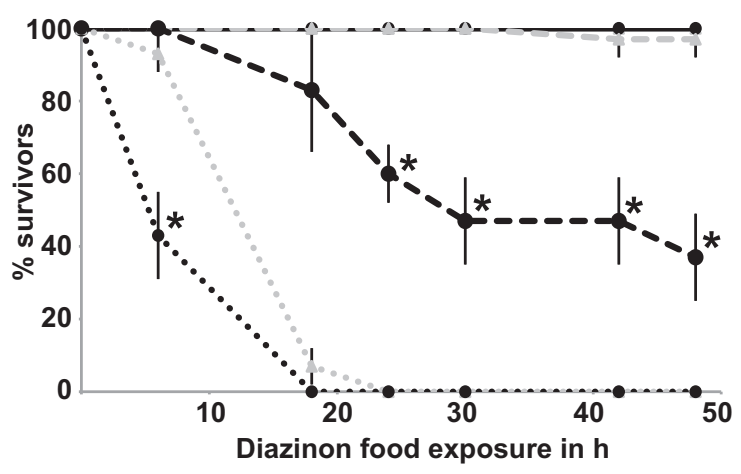

$0.1 \mathrm{ng} / \mu \mathrm{l}$

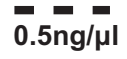

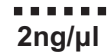

B

- $\alpha$-Est7:EGFP expression OFF (control)

$\Delta \alpha$-Est7:EGFP expression ON

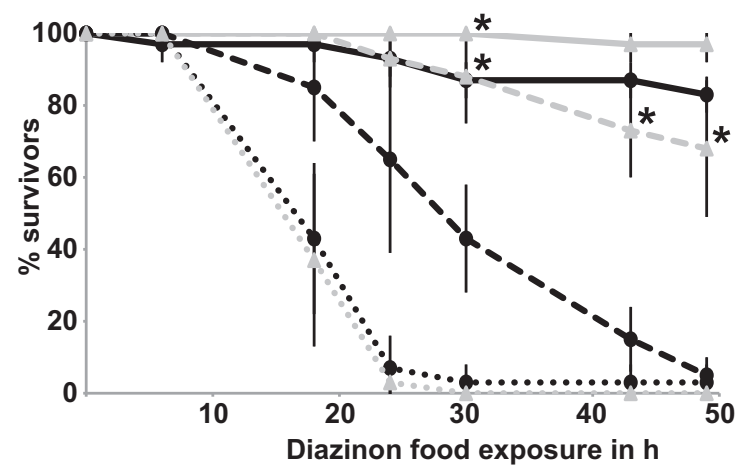

$1 \mathrm{ng} / \mu \mathrm{l}$

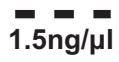

$2 \mathrm{ng} / \mu \mathrm{l}$

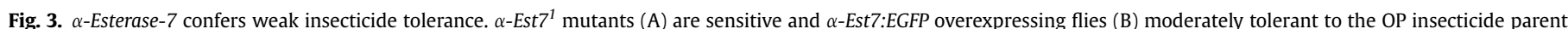

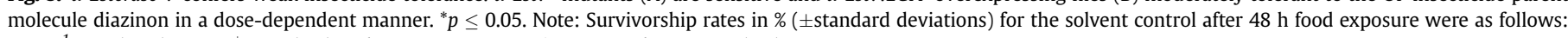
$\alpha$-Est7 $7^{1}=90( \pm 10), \alpha-E s t 7^{+}=95( \pm 5)$ and $\alpha$-Est7 overexpression OFF and ON $=100( \pm 0)$.

identity to CG1882 30.4\%) causes neutral lipid accumulation in plants (James et al., 2010). It should be noted, however, that due to the comparably low sequence conservation between the discussed fly proteins and their vertebrate or plant relatives predictions on analogous protein functions deserve caution. CG1882 is also conserved in a wide range of insect species such as the Coleopteran Tribolium castaneum (55.2\% sequence identity) and the pea aphid Acyrthosiphon pisum (47.8\% identity).

Besides candidate enzymes of fly neutral lipid metabolism the presented screen also identified CG18815, the only D. melanogaster homolog of mammalian lysophospholipases I and II (LYPLA1 and LYPLA2; also called acyl-protein thioesterase 1 and 2 (APT1 and APT2); sequence identity to CG18815 is $54.2 \%$ see Fig. S4). CG18815 is an abundantly expressed putative thioesterase with largely cytoplasmic localization according to fusion protein expression data in Drosophila S2 cell culture cells (Bannan et al., 2008). Both mammalian LYPLAs regulate signaling molecules by deacylation. For example, LYPLA1 deacylates the orexigenic peptide ghrelin in serum (Satou et al., 2010) and down-regulates the Ras protooncogene by depalmitoylation (Dekker et al., 2010). While LYPLA2 deacylates the growth-associated protein-43 (Tomatis et al., 2010). CG18815 is well conserved among Drosophilids (e.g. 93.1\% sequence identity to the $D$. grimshawi homolog) but also other insects such as the honeybee (60.2\% sequence identity; see Fig. S4). The biological function of CG18815, however, awaits characterization.

The most prominent constituents of the molecularly identified fat body esterolytic proteome are CEs encoded by the $\alpha$-Esterase and $\beta$-Esterase gene clusters. Among them is Esterase 6, a secreted esterase of the $\beta$-esterase cluster, which has an important though evolutionarily derived role in $D$. melanogaster reproduction. In this and closely related Drosophilid species the gene is expressed in the male ejaculatory duct from where Esterase 6 is transferred as part of the seminal fluid to the female during mating (Richmond et al., 1980). In the female, male-derived Esterase 6 translocates to the hemolymph (Meikle et al., 1990) and stimulates egg laying whereas female receptivity for remating is delayed. Currently unknown, however, is the function of the evolutionary ancient Esterase 6 activity in the hemolymph. This Esterase 6 protein pool likely originates from the fat body and has been identified at larval stages by activity staining (Healy et al., 1991) and proteomics (Vierstraete, 2003).

$\alpha$-Esterase-7 is among the evolutionary ancient members of the $\alpha$-Esterase cluster, which predicts important physiological gene functions (Oakeshott et al., 2005). To date, much of the current knowledge on Drosophila $\alpha$-Est7 function is derived from studies on $\alpha$-Est7 orthologs from insecticide-resistant strains of other dipteran species. In general, insecticide-resistant insect strains use one of two mechanisms to metabolically detoxify OP insecticides by $\mathrm{CE}$ activity modulation (reviewed in Feyereisen, 1995; Devonshire and Field, 1991; Ffrench-Constant et al., 2004; Oakeshott et al., 2005; Bass and Field, 2011). On one hand, overexpression of CEs by gene amplification or regulatory $\mathrm{CE}$ gene mutants confers OP tolerance by insecticide sequestration. This mechanism has been shown in resistant strains of aphids and lower dipteran insects (Field et al., 1999; Hemingway et al., 1998; Raymond et al., 1998) but also in the horn fly Haematobia irritans (Guerrero, 2000). On the other hand $\alpha$-Est7 can acquire insecticide tolerance by the mutant aliesterase mechanism (Oppenoorth and van Asperen, 1960), i.e. increased OP hydrolase activity by structural mutation of the

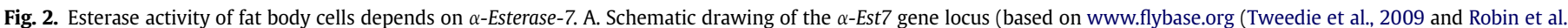

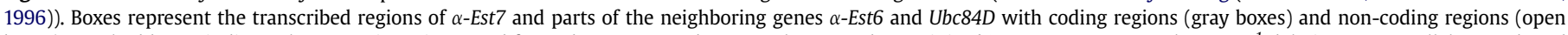

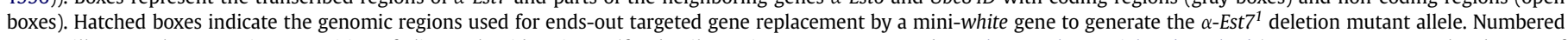

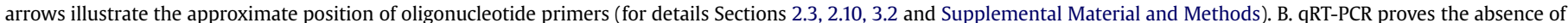

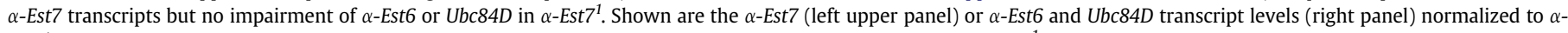

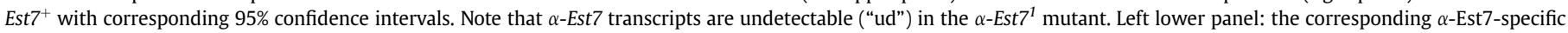

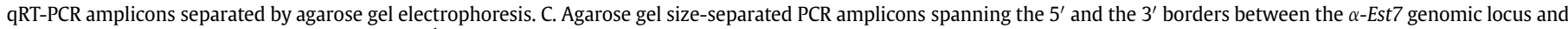

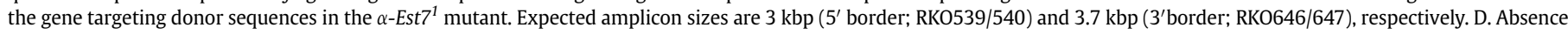

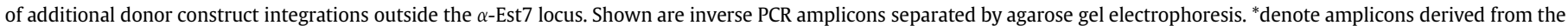

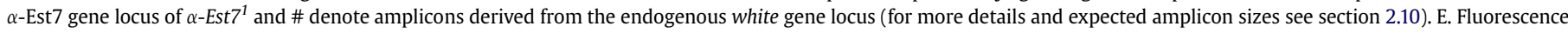

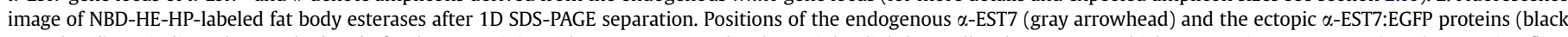

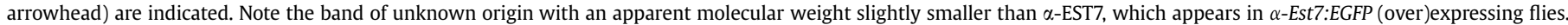

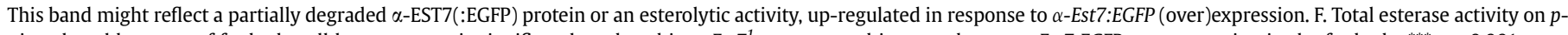
nitrophenyl butyrate of fat body cell homogenates is significantly reduced in $\alpha$-Est $7^{1}$ mutants and increased upon $\alpha$-Est7:EGFP overexpression in the fat body. ${ }^{* * *} p \leq 0.001$. 

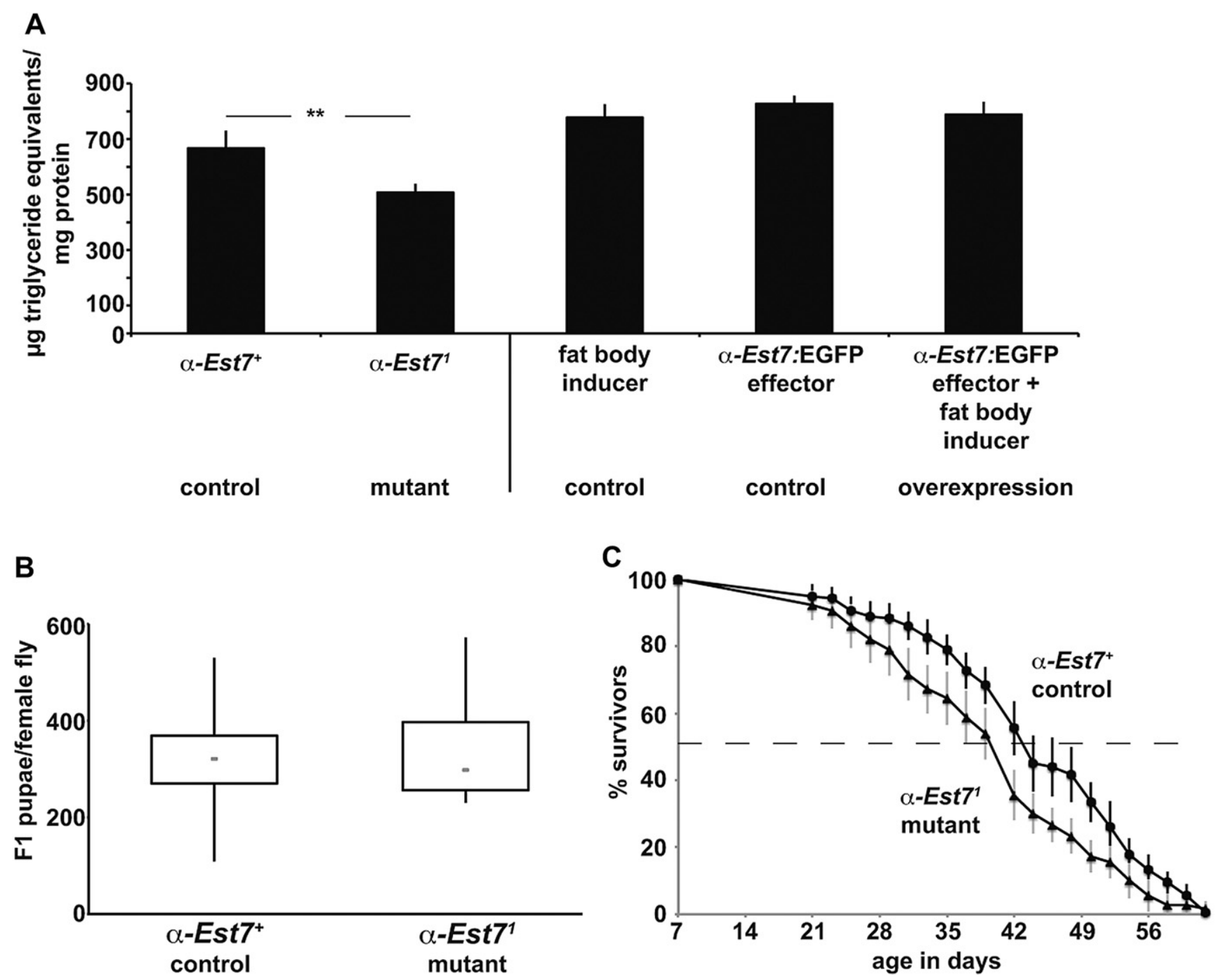

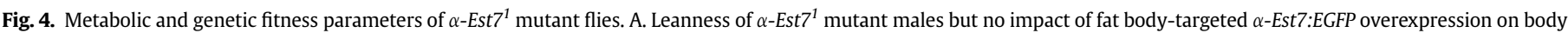

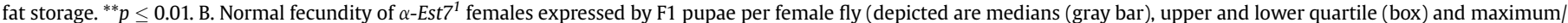

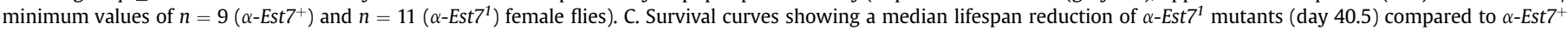

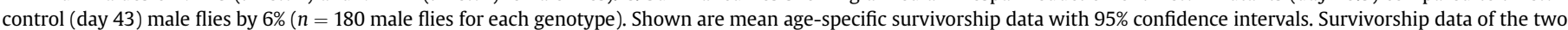

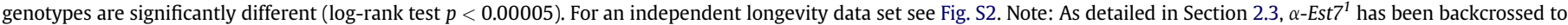
$\alpha-E s t 7^{+}$for four generations prior to analysis.

enzymes oxyanion hole at the expense of reduced CE activity. Aliesterase mutations in $\alpha$-Est7 are causative for metabolic resistance toward OP insecticides in several higher dipteran species including the housefly $M$. domestica (Claudianos et al., 1999) and the blowfly L. cuprina (Newcomb et al., 1997). By contrast, $\alpha$-EST7 mutants with mutant ali-esterase activity have not been found in OP-resistant D. melanogaster strains (Wilson, 2001). Instead, diazinon resistance of adult $D$. melanogaster from wild populations is low and of polygenic nature (Pyke et al., 2004). This seems paradoxical at first glance, because OP insecticide tolerance can be induced by transgenic expression of bacterial OP hydrolases in Drosophila (Phillips et al., 1990; Benedict et al., 1994), and because of the similar biochemical in vitro properties of the D.m. $\alpha$-Est7 and L.C. $\alpha$-Est7 isozymes (Parker et al., 1996). However, D.m. $\alpha$-Est7 shows low OP binding affinity compared to L.c. $\alpha$-EST7, which has been proposed to grant less protection for the insecticide target acetylcholinesterase in vivo (Parker et al., 1996). Our data provide evidence for a moderate dose-dependent OP-tolerance function of wild type $\alpha$-Est7, which is in line with these in vitro data. The primary sequence mutations in $\alpha$-EST7 found in OP-resistant insects have been demonstrated to confer mutant ali-esterase activity also to Drosophila $\alpha$-EST7 (Devonshire et al., 2003) and a broad range of distantly related CEs in vitro (Cui et al., 2011). The presented $\alpha$-Est7 null mutant fly opens the possibility to test the in vivo impact of $\alpha$-EST7 ali-esterase mutants on OP insecticide tolerance in Drosophila by a gene replacement strategy. This approach will also allow the analysis of possible selective disadvantages connected with the shift in substrate specificity.

Drosophila $\alpha$-Est7 mutants display a reduced body fat content, which invokes a role of the gene in lipid metabolism. In support of a lipid metabolic $\alpha$-Est7 function, $\alpha$-EST7 was identified on fat body lipid storage droplets (Beller et al., 2006) and the protein encodes an endoplasmic reticulum retention signal (Oakeshott et al., 2005), the organelle, where LDs are formed (Ohsaki et al., 2009). A number of LD-associated proteins in the fat body have been demonstrated to impact the body fat content in flies. Among them the triglyceride lipase Brummer (Grönke et al., 2005) and members of the Perilipin protein family, which are proposed to modulate lipase activity 
(Grönke et al., 2003; Teixeira et al., 2003; Beller et al., 2010). However, Drosophila $\alpha$-EST7 has low lipase activity (Campbell et al., 2003) and overexpression of the $\alpha$-Est7:EGFP fusion gene in the fat body does not affect the body fat content, which suggests that $\alpha$-Est7 is not sufficient for storage fat control in the fat body. Alternatively the gene could act at least in part outside the fat body to adjust body fat storage. Notably, $\alpha$-Est7 is also expressed in parts of the gut, in particular in the crop (Chintapalli et al., 2007), which serves as a temporary food storage organ in flies. Accordingly, it is tempting to speculate that improper food storage or processing might contribute to the observed leanness of $\alpha$-Est7 mutant flies. However, a mechanistic understanding of how $\alpha$-EST7 promotes neutral fat storage in flies requires the future identification of the in vivo substrates of the enzyme. It should be noted that differences in the body fat content might indirectly affect the toxicity of lipophilic OP insecticide parent molecules such as diazinon. Diazinon needs bioactivation (Pisani-Borg et al., 1996) typically by enzymes of the cytochrome P450 superfamily, some of which are expressed in the fat storage tissue (Chintapalli et al., 2007). Therefore it is tempting to speculate that a reduced fat content would cause decreased diazinon sequestration in the fat stores, which increases bioavailability of the parent molecule to activation to the OP insecticide diazoxon and accordingly would contribute to the moderately reduced insecticide tolerance level of the $\alpha$-Est $7^{1}$ mutant flies.

In the light of the complex ontogenetic expression profile of $\alpha$ Est7 from embryos to aged adult flies of both sexes and in various fly organs, the observed $\alpha$-Est7 mutant phenotype is comparably mild. Notwithstanding the fact that the phenotypic analysis of $\alpha$ Est7 mutants is not comprehensive, this observation might also reflect functional redundancy among the Drosophila $\alpha$-Est genes. Notably, EST9 encoded by the $\alpha$-Est5 gene is a fat body-expressed enzyme (Healy et al., 1991) and, consistently, $\alpha$-EST5 has been identified as fat body esterase by the presented functional proteomics approach (Fig. 1). In general, predictions regarding the in vivo functions of esterase genes deserve caution. Even a highly conserved gene such as Est-P (also called $\psi$ Est-6), a member of the $\beta$-Esterase cluster, is represented by functionally inactive alleles in many $D$. melanogaster wild populations suggesting no vital function of this gene, which might be in transition to a pseudogene in this species (Balakirev et al., 2003). This example emphasizes the need for a systematic generation and subsequent analysis of Esterase null mutants to assign functions to individual members of this important gene family. Accordingly, the presented initial phenotypic characterization of the $\alpha$-Est7 mutant pioneers the understanding of $\alpha$-Esterase in vivo gene functions. Important questions regarding e.g. the full spectrum of the $\alpha$-Est7 gene functions, the tissuespecificity or the endogenous substrate spectrum of the enzyme deserve future attention. Moreover, the Drosophila $\alpha$-Est7 deletion mutant paves the way for in vivo structure-function analyses using a gene replacement strategy.

\section{Funding}

This work was supported by the Max Planck Society (J.L., I.B., P.H. and R.P.K.) and the GOLD III (Genomics of Lipid associated Disorders III; http://gold.uni-graz.at/) project in the framework of GEN-AU (Genome research in Austria; http://www.gen-au.at/) funded by the Bundesministerium für Wissenschaft und Forschung (BM.W_F) (R.B.-G., A.H.).

\section{Author contributions}

The study was designed by R.P.K. and R.B.-G. All fly experiments were done by I.B., J.L., P.H. and R.P.K. Functional proteomics was performed by R.B.-G., M.K., G.N.R. and A.H., R.P.K, P.H. and R.B.-G. analyzed the data and wrote the manuscript.

\section{Conflict of interest}

The authors declare no competing financial interests.

\section{Acknowledgments}

The authors thank Jeff Sekelsky for plasmids and the Bloomington Drosophila Stock Center for fly stocks. The authors are grateful to Sebastian Grönke for advice on lifespan analyses. Herbert Jäckle is acknowledged for constant support and three anonymous reviewers for noteworthy constructive criticism on a previous version of the manuscript.

\section{Appendix. Supplementary material}

Supplementary data associated with this article can be found, in the online version, at doi:10.1016/j.ibmb.2011.12.004.

\section{References}

Balakirev, E.S., Chechetkin, V.R., Lobzin, V.V., Ayala, F.J., 2003. DNA polymorphism in the beta-Esterase gene cluster of Drosophila melanogaster. Genetics 164, 533-544.

Bannan, B.A., Van Etten, J., Kohler, J.A., Tsoi, Y., Hansen, N.M., Sigmon, S., Fowler, E. Buff, H., Williams, T.S., Ault, J.G., et al., 2008. The Drosophila protein palmitoylome: characterizing palmitoyl-thioesterases and DHHC palmitoyl-transferases. Fly 2, 198-214.

Bass, C., Field, L.M., 2011. Gene amplification and insecticide resistance. Pest Manag. Sci. 67, 886-890.

Beller, M., Riedel, D., Jänsch, L., Dieterich, G., Wehland, J., Jäckle, H., Kühnlein, R.P., 2006. Characterization of the Drosophila lipid droplet subproteome. Mol. Cell. Proteomics 5, 1082-1094.

Beller, M., Bulankina, A.V., Hsiao, H.-H., Urlaub, H., Jäckle, H., Kühnlein, R.P., 2010. PERILIPIN-dependent control of lipid droplet structure and fat storage in Drosophila. Cell Metab. 12, 521-532.

Benedict M.Q. Scott, JA, Cockburn, A.F, 1994. High-level expression of the bacterial opd gene in Drosophila melanogaster: improved inducible insecticide resistance. Insect Mol. Biol. 3, 247-252.

Birner-Gruenberger, R., Susani-Etzerodt, H., Kollroser, M., Rechberger, G.N. Hermetter, A., 2008. Lipolytic and esterolytic activity-based profiling of murine liver. Proteomics 8, 3645-3656.

Birner-Gruenberger, R., Susani-Etzerodt, H., Waldhuber, M., Riesenhuber, G., Schmidinger, H., Rechberger, G., Kollroser, M., Strauss, J., Lass, A. Zimmermann, R., et al., 2005. The lipolytic proteome of mouse adipose tissue. Mol. Cell. Proteomics 4, 1710-1717.

Brand, A., Perrimon, N., 1993. Targeted gene expression as a means of altering cell fates and generating dominant phenotypes. Development 118, 401-415.

Campbell, P.M., de Q Robin, G.C., Court, L.N., Dorrian, S.J., Russell, R.J., Oakeshott, J.G., 2003. Developmental expression and gene/enzyme identifications in the alpha esterase gene cluster of Drosophila melanogaster. Insect Mol. Biol. 12, 459-471.

Carr, S., Aebersold, R., Baldwin, M., Burlingame, A., Clauser, K., Nesvizhskii, A., Working Group on Publication Guidelines for Peptide and Protein Identification Data, 2004. The need for guidelines in publication of peptide and protein identification data: working group on publication guidelines for peptide and protein identification data. Mol. Cell. Proteomics 3, 531-533.

Cermelli, S., Guo, Y., Gross, S.P., Welte, M.A., 2006. The lipid-droplet proteome reveals that droplets are a protein-storage depot. Curr. Biol. 16, 1783-1795.

Chintapalli, V.R., Wang, J., Dow, J.A.T., 2007. Using FlyAtlas to identify better Drosophila melanogaster models of human disease. Nat. Genet. 39, 715-720.

Clarke, G.M., Yen, J.L., McKenzie, J.A., 2000. Wings and bristles: character specificity of the asymmetry phenotype in insecticide-resistant strains of Lucilia cuprina. Proc. Biol. Sci. 267, 1815-1818.

Claudianos, C., Russell, R.J., Oakeshott, J.G., 1999. The same amino acid substitution in orthologous esterases confers organophosphate resistance on the house fly and a blowfly. Insect Biochem. Mol. Biol. 29, 675-686.

Cui, F., Lin, Z., Wang, H., Liu, S., Chang, H., Reeck, G., Qiao, C., Raymond, M., Kang, L. 2011. Two single mutations commonly cause qualitative change of nonspecific carboxylesterases in insects. Insect Biochem. Mol. Biol. 41, 1-8.

Davies, A.G., Game, A.Y., Chen, Z., Williams, T.J., Goodall, S., Yen, J.L., McKenzie, J.A. Batterham, P., 1996. Scalloped wings is the Lucilia cuprina Notch homologue and a candidate for the modifier of fitness and asymmetry of diazinon resistance. Genetics 143, 1321-1337.

Dekker, F.J., Rocks, O., Vartak, N., Menninger, S., Hedberg, C., Balamurugan, R., Wetzel, S., Renner, S., Gerauer, M., Schölermann, B., et al., 2010. Small-molecule 
inhibition of APT1 affects Ras localization and signaling. Nat. Chem. Biol. 6, 449-456.

Devonshire, A.L., Heidari, R., Bell, K.L., Campbell, P.M., Campbell, B.E., Odgers, W.A., Oakeshott, J.G., Russell, R.J., 2003. Kinetic efficiency of mutant carboxylesterases implicated in organophosphate insecticide resistance. Pestic. Biochem. Physiol. $76,1-13$.

Devonshire, A.L., Field, L.M., 1991. Gene amplification and insecticide resistance. Annu. Rev. Entomol. 36, 1-23.

Dierick, H.A., Greenspan, R.J., 2006. Molecular analysis of flies selected for aggressive behavior. Nat. Genet. 38, 1023-1031.

Ellis, L.L., Carney, G.E., 2010. Mating alters gene expression patterns in Drosophild melanogaster male heads. BMC Genomics 11, 558.

Feyereisen, R., 1995. Molecular biology of insecticide resistance. Toxicol. Lett. 82-83, 83-90.

Ffrench-Constant, R.H., Daborn, P.J., Le Goff, G., 2004. The genetics and genomics of insecticide resistance. Trends Genet. 20, 163-170.

Field, L.M., Blackman, R.L., Tyler-Smith, C., Devonshire, A.L., 1999. Relationship between amount of esterase and gene copy number in insecticide-resistant Myzus persicae (Sulzer). Biochem. J. 339 (3), 737-742.

Ghosh, A.K., Ramakrishnan, G., Chandramohan, C., Rajasekharan, R., 2008. CGI-58, the causative gene for Chanarin-Dorfman syndrome, mediates acylation of lysophosphatidic acid. J. Biol. Chem. 283, 24525-24533.

Gong, W., Golic, K., 2003. Ends-out, or replacement, gene targeting in Drosophila. Proc. Natl. Acad. Sci. U S A 100, 2556-2561.

Grönke, S., Mildner, A., Fellert, S., Tennagels, N., Petry, S., Müller, G., Jäckle, H. Kühnlein, R.P., 2005. Brummer lipase is an evolutionary conserved fat storage regulator in Drosophila. Cell Metab. 1, 323-330.

Grönke, S., Beller, M., Fellert, S., Ramakrishnan, H., Jäckle, H., Kühnlein, R.P., 2003. Control of fat storage by a Drosophila PAT domain protein. Curr. Biol. 13, 603-606.

Grönke, S., Bickmeyer, I., Wunderlich, R., Jäckle, H., Kühnlein, R.P., 2009. Curled encodes the Drosophila homolog of the vertebrate circadian deadenylase nocturnin. Genetics 183, 219-232.

Grönke, S., Müller, G, Hirsch, J., Fellert, $S$, Andreou, A., Haase, T., Jäckle, $H$. Kühnlein, R.P., 2007. Dual lipolytic control of body fat storage and mobilization in Drosophila. PLoS Biol. 5, e137.

Guerrero, F.D., 2000. Cloning of a horn fly cDNA, HialphaE7, encoding an esterase whose transcript concentration is elevated in diazinon-resistant flies. Insect Biochem. Mol. Biol. 30, 1107-1115.

Healy, M.J., Dumancic, M.M., Oakeshott, J.G., 1991. Biochemical and physiological studies of soluble esterases from Drosophila melanogaster. Biochem. Genet. 29, 365-388.

Heidari, R., Devonshire, A.L., Campbell, B.E., Bell, K.L., Dorrian, S.J., Oakeshott, J.G. Russell, R.J., 2004. Hydrolysis of organophosphorus insecticides by in vitro modified carboxylesterase E3 from Lucilia cuprina. Insect Biochem. Mol. Biol. 34 353-363.

Hemingway, J., Hawkes, N., Prapanthadara, L., Jayawardenal, K.G., Ranson, H., 1998. The role of gene splicing, gene amplification and regulation in mosquito insecticide resistance. Philos. Trans. R. Soc. Lond. B: Biol. Sci. 353, 1695-1699.

Hildebrandt, A., Bickmeyer, I., Kühnlein, R.P., 2011. Reliable Drosophila body fat quantification by a coupled colorimetric assay. PLoS ONE 6, e23796.

James, C.N., Horn, P.J., Case, C.R., Gidda, S.K., Zhang, D., Mullen, R.T., Dyer, J.M., Anderson, R.G.W., Chapman, K.D., 2010. Disruption of the Arabidopsis CGI-58 homologue produces Chanarin-Dorfman-like lipid droplet accumulation in plants. Proc. Natl. Acad. Sci. U S A 107, 17833-17838.

Lass, A., Zimmermann, R., Haemmerle, G., Riederer, M., Schoiswohl, G. Schweiger, M., Kienesberger, P., Strauss, J.G., Gorkiewicz, G., Zechner, R., 2006. Adipose triglyceride lipase-mediated lipolysis of cellular fat stores is activated by CGI-58 and defective in Chanarin-Dorfman syndrome. Cell Metab. 3, 309-319.

Marchler-Bauer, A., Lu, S., Anderson, J.B., Chitsaz, F., Derbyshire, M.K., DeWeeseScott, C., Fong, J.H., Geer, L.Y., Geer, R.C., Gonzales, N.R., et al., 2011. CDD a conserved domain database for the functional annotation of proteins. Nucleic Acids Res. 39, D225-D229.

McKenzie, J.A., Whitten, M.J. Adena, M.A., 1982. The effect of genetic background on the fitness of diazinon resistance genotypes of the Australian sheep blowfly, Lucilia cuprina. Heredity 49, 1-9.

McKenzie, J.A., Clarke, G.M., 1988. Diazinon resistance, fluctuating asymmetry and fitness in the Australian sheep blowfly, Lucilia cuprina. Genetics 120, 213-220.

Meikle, D., Sheehan, K., Phillis, D., Richmond, R., 1990. Localization and longevity of seminal-fluid esterase 6 in mated female Drosophila melanogaster. J. Insect Physiol. 36, 93-100.

Newcomb, R.D., Campbell, P.M., Ollis, D.L., Cheah, E., Russell, R.J., Oakeshott, J.G., 1997. A single amino acid substitution converts a carboxylesterase to an organophosphorus hydrolase and confers insecticide resistance on a blowfly. Proc. Natl. Acad. Sci. U S A 94, 7464-7468.

Nomura, D.K., Dix, M.M., Cravatt, B.F., 2010. Activity-based protein profiling for biochemical pathway discovery in cancer. Nat. Rev. Cancer 10, 630-638.

Oakeshott, J.G., Claudianos, C., Campbell, P.M., Newcomb, R.D., Russell, R.J., 2005 Biochemical genetics and genomics of insect esterases. In: Gilbert, L.I., Iatrou, K.,
Gill, S.S. (Eds.), Comprehensive Molecular Insect Science. Elsevier, Amsterdam, pp. 309-383.

Oakeshott, J.G., Claudianos, C., Russell, R.J., Robin, G.C., 1999. Carboxyl/cholinesterases: a case study of the evolution of a successful multigene family. BioEssays 21, 1031-1042.

Ohsaki, Y., Cheng, J., Suzuki, M., Shinohara, Y., Fujita, A., Fujimoto, T., 2009. Biogenesis of cytoplasmic lipid droplets: from the lipid ester globule in the membrane to the visible structure. Biochim. Biophys. Acta 1791, 399-407.

Oppenoorth, F.J., van Asperen, K., 1960. Allelic genes in the housefly producing modified enzymes that cause organophosphate resistance. Science 132, 298-299.

Oskolkova, O.V., Saf, R., Zenzmaier, E., Hermetter, A., 2003. Fluorescent organophosphonates as inhibitors of microbial lipases. Chem. Phys. Lipids 125, 103-114.

Palmer, A.R., Strobeck, C., 1986. Fluctuating asymmetry: measurement, analysis, patterns. Annu. Rev. Ecol. Syst. 17 (1), 391-421.

Parker, A., Campbell, P., Spackman, M., Russell, R., Oakeshott, J., 1996. Comparison of an esterase associated with organophosphate resistance in Lucilia cuprina with an orthologue not associated with resistance in Drosophila melanogaster. Pestic. Biochem. Physiol. 55, 85-99.

Parsons, P.A., 1962. Maternal age and developmental variability. J. Exp. Biol. 39, 251-260.

Phillips, J.P., Xin, J.H., Kirby, K., Milne, C.P., Krell, P., Wild, J.R., 1990. Transfer and expression of an organophosphate insecticide-degrading gene from Pseudomonas in Drosophila melanogaster. Proc. Natl. Acad. Sci. U S A 87, 8155-8159.

Pisani-Borg, E., Cuany, A., Brun, A., Amichot, M., Fournier, D., Berge, J.B., 1996. Oxidative degradation of diazinon by Drosophila: metabolic changes associated with insecticide resistance and induction. Pestic. Biochem. Physiol. 54, 56-64.

Polak, M., Kroeger, D.E., Cartwright, I.L., Ponce deLeon, C., 2004. Genotype-specific responses of fluctuating asymmetry and of preadult survival to the effects of lead and temperature stress in Drosophila melanogaster. Environ. Pollut. 127 (1), 145-155.

Pyke, F.M., Bogwitz, M.R., Perry, T., Monk, A., Batterham, P., McKenzie, J.A., 2004. The genetic basis of resistance to diazinon in natural populations of Drosophila melanogaster. Genetica 121, 13-24.

Ranson, H., Claudianos, C., Ortelli, F., Abgrall, C., Hemingway, J., Sharakhova, M.V., Unger, M.F., Collins, F.H., Feyereisen, R., 2002. Evolution of supergene families associated with insecticide resistance. Science 298, 179-181.

Raymond, M., Chevillon, C., Guillemaud, T., Lenormand, T., Pasteur, N., 1998. An overview of the evolution of overproduced esterases in the mosquito Culex pipiens. Philos. Trans. R Soc. Lond B. Biol. Sci. 353, 1707-1711.

Richmond, R.C., Gilbert, D.G., Sheehan, K.B., Gromko, M.H., Butterworth, F.M., 1980. Esterase 6 and reproduction in Drosophila melanogaster. Science 207, 1483-1485.

Robin, C., Russell, R.J., Medveczky, K.M., Oakeshott, J.G., 1996. Duplication and divergence of the genes of the alpha-esterase cluster of Drosophila melanogaster. J. Mol. Evol. 43, 241-252.

Satou, M., Nishi, Y., Yoh, J., Hattori, Y., Sugimoto, H., 2010. Identification and characterization of acyl-protein thioesterase 1/Lysophospholipase I as a ghrelin deacylation/lysophospholipid hydrolyzing enzyme in fetal bovine serum and conditioned medium. Endocrinology 151, 4765-4775.

Schmidinger, H., Birner-Gruenberger, R., Riesenhuber, G., Saf, R., Susani-Etzerodt, H., Hermetter, A., 2005. Novel fluorescent phosphonic acid esters for discrimination of lipases and esterases. ChemBioChem 6,1776-1781.

Shen, W., Patel, S., Yu, Z., Jue, D., Kraemer, F., 2007. Effects of rosiglitazone and high fat diet on lipase/esterase expression in adipose tissue. Biochim. Biophys. Acta $1771,177-184$

Shevchenko, A., Wilm, M., Vorm, O., Mann, M., 1996. Mass spectrometric sequencing of proteins silver-stained polyacrylamide gels. Anal. Chem. 68, 850-858.

Shirai, K., Jackson, R.L., 1982. Lipoprotein lipase-catalyzed hydrolysis of p-nitrophenyl butyrate. Interfacial activation by phospholipid vesicles. J. Biol. Chem. 257, 1253-1258.

Spackman, M.E., Oakeshott, J.G., Smyth, K.A., Medveczky, K.M., Russell, R.J., 1994. A cluster of esterase genes on chromosome $3 \mathrm{R}$ of Drosophila melanogaster includes homologues of esterase genes conferring insecticide resistance in Lucilia cuprina. Biochem. Genet. 32, 39-62.

Teixeira, L., Rabouille, C., Rørth, P., Ephrussi, A., Vanzo, N.F., 2003. Drosophila Perilipin/ADRP homologue Lsd2 regulates lipid metabolism. Mech. Dev. 120, 1071-1081.

Tomatis, V.M., Trenchi, A., Gomez, G.A., Daniotti, J.L., 2010. Acyl-protein thioesterase 2 catalyzes the deacylation of peripheral membrane-associated GAP-43. PLoS ONE 5, e15045.

Tweedie, S., Ashburner, M., Falls, K., Leyland, P., McQuilton, P., Marygold, S., Millburn, G., Osumi-Sutherland, D., Schroeder, A., Seal, R., et al., 2009. FlyBase: enhancing Drosophila gene ontology annotations. Nucleic Acids Res. 37, D555-D559.

Vierstraete, E., 2003. Proteomics in Drosophila melanogaster: first 2D database of larval hemolymph proteins. Biochem. Biophys. Res. Commun. 304, 831-838.

Wilson, T.G, 2001. Resistance of Drosophila to toxins. Annu. Rev. Entomol. 46, 545-571. 